\title{
Erratum to: Carnitine levels in 26,462 individuals from the nationwide screening program for primary carnitine deficiency in the Faroe Islands
}

\author{
Jan Rasmussen • Olav W. Nielsen • Nils Janzen • \\ Morten Duno • Hannes Gislason • Lars Køber • \\ Ulrike Steuerwald • Allan M. Lund
}

Published online: 1 May 2014

(C) SSIEM and Springer Science+Business Media Dordrecht 2014

\section{Erratum to: J Inherit Metab Dis}

\section{DOI 10.1007/s10545-013-9606-2}

One of the authors, Hannes Gislason, was inadvertently omitted from the manuscript supplied for publication. This error is rectified here.

The online version of the original article can be found at http://dx.doi.org/ 10.1007/s10545-013-9606-2.

J. Rasmussen $(\bowtie)$

Department of Internal Medicine, National Hospital, FO-100,

Thorshavn, Faroe Islands

e-mail:1sjanra@1s.fo

O. W. Nielsen

Department of Cardiology, Bispebjerg University Hospital,

Copenhagen, Denmark

N. Janzen $\cdot$ U. Steuerwald

Screening-Labor Hannover, Hannover, Germany

\section{N. Janzen}

Department of Neuropediatrics, Children's Hospital, Ruhr

University of Bochum, Bochum, Germany

N. Janzen

Clinic for Pediatric Kidney-, Liver- and Metabolic Diseases,

Hannover Medical School, Hannover, Germany
M. Duno $\cdot$ A. M. Lund

Centre for Inherited Metabolic Disorders, Department of Clinical Genetics, Rigshospitalet University Hospital,

Copenhagen, Denmark

\section{H. Gislason}

Faculty of Natural and Health Sciences, University of the Faroe Islands, Torshavn, Faroe Islands

\section{Køber}

Department of Cardiology, Rigshospitalet University Hospital, Copenhagen, Denmark

\section{U. Steuerwald}

Department of Occupational and Public Health, National Hospital System, Thorshavn, Faroe Islands 